\title{
Frequency of CHEK2*I I 00delC in New York breast cancer cases and controls
}

\author{
Kenneth Offit*1, Heather Pierce ${ }^{1}$, Tomas Kirchhoff1, Prema Kolachana1, \\ Beth Rapaport ${ }^{1}$, Peter Gregersen ${ }^{2}$, Steven Johnson ${ }^{3}$, Orit Yossepowitch ${ }^{1}$, \\ Helen Huang1, Jaya Satagopan ${ }^{1}$, Mark Robson ${ }^{1}$, Lauren Scheuer ${ }^{1}$, \\ Khedoudja Nafa ${ }^{1}$ and Nathan Ellis ${ }^{1}$
}

\begin{abstract}
Address: ${ }^{1}$ Departments of Medicine and Biostatistics and Epidemiology, Memorial Sloan-Kettering Cancer Center, New York, N.Y, USA, ${ }^{2}$ Center for Genomics and Human Genetics, North Shore Long Island Jewish Research Institute, Manhasset, N.Y, USA and ${ }^{3}$ Department of Bioinformatics, Columbia University, New York, N.Y, USA

Email: Kenneth Offit* - offitk@mskcc.org; Heather Pierce - pierceh@mskcc.org; Tomas Kirchhoff - kirchhot@mskcc.org;

Prema Kolachana - kolachap@mskcc.org; Beth Rapaport - rapaporb@mskcc.org; Peter Gregersen - peterg@nshs.edu;

Steven Johnson - johnson@dmi.columbia.edu; Orit Yossepowitch - orityossepowitch@ hotmail.com; Helen Huang - huangh@mskcc.org;

Jaya Satagopan - satagopj@mskcc.org; Mark Robson - robsonm@mskcc.org; Lauren Scheuer - scheuerl@mskcc.org;

Khedoudja Nafa - nafak@mskcc.org; Nathan Ellis - ellisn@mskcc.org

* Corresponding author
\end{abstract}

Published: 15 January 2003

BMC Medical Genetics 2003, 4:I

This article is available from: http://www.biomedcentral.com/I47I-2350/4/I

(C) 2003 Offit et al; licensee BioMed Central Ltd. This is an Open Access article: verbatim copying and redistribution of this article are permitted in all media for any purpose, provided this notice is preserved along with the article's original URL.
Received: 17 October 2002

Accepted: 15 January 2003

\begin{abstract}
Background: The I I 00de/C CHEK2 allele has been associated with a I.4-4.7 fold increased risk for breast cancer in women carrying this mutation. While the frequency of I I O00delC was I.I-I.4\% in healthy Finnish controls, the frequency of this allele in a North American control population and in North American breast cancer kindreds remains unclear.

Methods: We genotyped 1665 healthy New York volunteers and 300 cases of breast cancer for the CHEK2*I l o0delC.

Results: The overall frequency of the I I00delC was 3/300 (I.0\%) among all cases with either a family history of breast cancer $(n=192)$ or a personal history of breast cancer $(n=108$, of which 46 were bilateral, 46 unilateral, and 16 were male breast cancer cases), compared to a frequency of $5 / 1665(0.3 \%)$ in healthy controls $(p=0.1)$. There was no difference in allele frequency among Ashkenazi and non-Ashkenazi controls.

Conclusion: The relatively low breast cancer penetrance of this allele, along with the low population frequency, will limit the clinical applicability of germline testing for CHEK2*I I00delC in North American kindreds.
\end{abstract}

\section{Background}

In response to DNA damage, the cell-cycle checkpoint kinase CHEK2 can be activated by ATM kinase to phosphorylate $p 53$ and BRCA1, which are involved in cell-cycle control, apoptosis, and DNA repair [1,2]. A germline mu- tation 1100delC truncates the CHEK2 protein and was first observed in families exhibiting Li-Fraumeni syndrome [3]. To address the possibility that this allele contributes to increased susceptibility to breast cancer, two recent studies have investigated the frequency of 
CHEK2*1100delC in cancer cases and controls. Vahteristo et al. [4] reported that the $1100 \mathrm{delC}$ protein-truncating mutation of CHEK2 was observed in $5.5 \%$ of 507 patients with a family history of breast cancer and no detectable BRCA mutation compared to $1.4 \%$ of 1,885 healthy Finnish controls. The CHEK2-Breast Cancer Consortium observed a $5.1 \%$ frequency of this allele in 1071 individuals with breast cancer derived from multiple-case families in which no mutations in BRCA1 or BRCA2 were detected, compared to a $1.1 \%$ of 1,620 healthy (mostly Northern European) controls [5]. These two groups also reported an increased frequency of $\mathrm{CHEK} 2{ }^{*} 1100 \mathrm{del} C$ in kindreds with male breast cancer or bilateral breast cancer. We report here the frequency of CHEK2* 1100 delC in North American breast cancer patients and controls.

\section{Methods}

We have analyzed a North American sample of healthy controls participating in the New York Cancer Project, and two series of cases: those enrolled in a genetic counseling clinic as well as a separate series of cases unselected for family history ascertained at Memorial Sloan-Kettering Cancer Center. The cases and controls self-identified themselves as Jewish or non-Jewish and reported their ancestor's countries of origin. The population control samples were derived from the New York Cancer Project, an ongoing cohort study enrolling healthy volunteers. Of the 569 non-Ashkenazi controls participating in this study, 62 were African-American, 37 Hispanic, 20 Asian, 18 Other/ Unknown, and 432 Caucasian. All individuals in this study provided informed consent for future DNA analysis. Genomic DNA was extracted and amplified utilizing CHEK2 external PCR primers:

\section{Fe 5' CTGTCATCTCAAGAAGAGGACT and}

\section{R 5' ATTTGTGACTTCATCTAATCACCTCC}

and internal PCR primers:

\section{F 5' TGGCAAGTTCAACATTATTCCC and}

\section{Re 5' GAATAACTCCTAAACTCCAGC}

Genotyping was performed by dHPLC (Transgenomics, USA) or Pyrosequencing (Pyrosequencing, Inc. Sweden); all mutations were confirmed by both of these methodologies. Non-Ashkenazi individuals were screened by DNA sequencing for mutations in the entire BRCA1 and BRCA2 coding sequence and Ashkenazi individuals were screened for the three founder alleles that account for $>95 \%$ of mutations in this ethnic group [6].

\section{Results}

We observed CHEK2*1100delC in 5/1665 (0.3\%) of healthy New York City controls, significantly lower than the frequency in controls reported by Vahteristo et al. ( $\mathrm{p}=$ 0.0004 , Fisher's Exact test) or by the CHEK2 Consortium $(\mathrm{p}=0.006)$. Within our sample, 3/1096 (0.3\%) individuals of Jewish (predominantly Ashkenazi) descent carried this allele, a rate comparable to the $0.4 \%$ frequency (2/ $569)$ observed in individuals of non-Ashkenazi descent. We detected $\mathrm{CHEK} 2{ }^{*} 1100 \mathrm{delC}$ in $1 / 100$ index cases from multiple-case breast cancer families in which mutations in BRCA1 or BRCA2 were not detected. As noted in Table 1, the one case heterozygous for the 1100delC was an individual of Ashkenazi descent seen at our Center who was previously included in the report by the CHEK2-Breast Cancer Consortium. Of these 100 families, 33 were of Ashkenazi descent and 67 were of non-Ashkenazi origin. CHEK2*1100delC was detected in 0/16 male individuals with breast cancer without mutations in BRCA2, and in 1/ $46(2.2 \%)$ of clinic-ascertained bilateral breast cancer cases in individuals with a family history of breast cancer who were also of Ashkenazi Jewish descent compared to 0/46 clinic-ascertained unilateral breast cancer cases matched by age, ethnicity and family history. In a separate series of bilateral breast cancer cases unselected for family history, 0/46 carried CHEK2 ${ }^{*} 1100$ delC, compared to $1 / 46$ unilateral breast cancer cases matched to the bilateral cases by age and ethnicity. Taking all of the breast cancer cases combined, the frequency of the 1100 delC was $3 / 300$ $(1.0 \%)$ compared to the population frequency of $5 / 1665$ $(0.3 \%)(\mathrm{p}=0.10)$.

\section{Discussion}

Our current findings do not exclude the possibility that the $C H E K 2 * 1100$ delC variant increases the relative risk for breast cancer in North Americans. Because this variant occurs significantly less commonly in healthy New York controls compared to Northern European controls, the low frequency of this allele in multiple-case families, bilateral cases, and male breast cancer cases could still be compatible with a relative risk in the range of 3.5-12 as reported by Vahteristo et al. and the CHEK2-Breast Cancer Consortium.

A prior attempt to analyze the entire CHEK2 gene in a northern European cohort was unable to detect mutations in exons $10-14$, including the $1100 \mathrm{delC}$, in $79 \mathrm{BRCA1/2}$ negative individuals from Finnish families with three or more cases of breast cancer [7]. The relative size of the population control samples in our studies was comparable to prior studies $(1,620$ population controls in the CHEK2-Consortium, 1,885 in Vahteristo et al, and 1,665 in the current study). We evaluated 100 BRCA mutationnegative breast cancer families, compared to 216 in the report by Vahteristo et al, and 718 in the Consortium study. 
Table I: CHEK2*II00deIC in breast cancer cases and healthy controls

Positive for CHEK2*I I00delC (\%)

$\begin{array}{lc}\text { Controls } & \\ \text { Jewish (New York) } & 3 / 1096(0.3 \%) \\ \text { Non-Jewish (New York) } & 2 / 569(0.4 \%) \\ \text { Total } & 5 / 1665(0.3 \%) \\ \text { BRCA I/2-negative individuals of mixed ethnicity with breast cancer from families with 3 or more cases of breast } & 0 / 67(0.0 \%) \\ \text { cancer } & 1 / 33 \#(3.0 \%) \\ \text { BRCAI/2 Ashkenazi founder mutation-negative individuals with breast cancer from families with 3 or more } & \\ \text { cases of breast cancer } & 0 / 16(0.0 \%) \\ \text { BRCA2-negativei individuals of mixed ethnicity with male breast cancer } & 0 / 46(0.0 \%) \\ \text { Individuals with bilateral breast cancer of mixed ethnicity unselected for family history } & 1 / 46(2.2 \%) \\ \text { Individuals with unilateral breast cancer unselected for family history matched for age, ethnicity } & 1 / 46(2.2 \%) \\ \text { Clinic-ascertained individuals of Ashkenazi Jewish descent with bilateral breast cancer } & 0 / 46(0.0 \%) \\ \text { Clinic-ascertained individuals of Ashkenazi Jewish descent with unilateral breast cancer matched for age, family } & \\ \text { history } & \end{array}$

\#This case previously reported in CHEK2 Breast Cancer Consortium [5].

However, our report also utilized the hypothesis proposed by Begg et al [8], of an "enrichment" of germline carriers of cancer predisposition alleles in individuals with bilateral breast cancer. Our series analyzed 92 cases of bilateral breast cancer and 92 controls, compared to 33 bilateral breast cancer cases included in the report by Vahteristo et al. While no enrichment was noted in our bilateral cases compared to unilateral cases, this may also reflect the lower population frequency of the allele in our population.

Further study of the frequency of the CHEK $2 * 1100 \mathrm{delC}$ allele in North American breast cancer kindreds is warranted, however, the relative rarity of this allele in our population, plus the relatively low breast cancer penetrance reported for this allele, limit the clinical relevance in North American kindreds of CHEK2*1100delC as a cancer-predisposing allele.

\section{Conclusions}

The $0.3 \%$ frequency of the 1100delC CHEK2 allele in a New York population is significantly lower than the 1.1$1.4 \%$ rate observed in Northern European populations. This allele was infrequent in BRCA1/2 wild-type cases with family history of breast cancer or in cases with a personal history of unilateral or bilateral of breast cancer. The relatively low breast cancer penetrance, along with the low population frequency, limit the clinical relevance in North American kindreds of CHEK2*1100delC as a cancer predisposing allele.

\section{Competing interests}

None declared.

\section{Authors' contributions}

KO designed the study and wrote the final draft of the paper; HP helped in the design and coordinated specimen collection; TK, KN, and PK performed genotype analysis and wre supervised by NE who also participated in study design; BR wrote the first draft of the manuscript and coordinated data collection; PK and SG oversaw collection of control samples and participated in study design; OY ascertained the familial breast cases and helped with study design; HH helped with data collection and analysis, JS provided biostatistical analysis; MR and LS participated in study design and analysis.

\section{Acknowledgments}

The authors would like to acknowledge the New York Cancer Project, which in connection with the publication of this study made available biological samples from and information on control individuals. The New York Cancer Project is administered and funded by AMDeC Foundation, Inc. We also acknowledge support of the Koodish Fellowship, the Frankel Foundation, the Lymphoma Foundation and the Danziger Foundation.

\section{References}

I. Chehab NH, Malikzay A, Appel M and Halazonetis TD Chk2/hCds I functions as a DNA damage checkpoint in $\mathbf{G}(I)$ by stabilizing p53. Genes Dev 2000, 14:278-288

2. Lee JS, Collins KM, Brown AL, Lee $\mathrm{CH}$ and Chung JH hCds/-mediated phosphorylation of $B R C A I$ regulates the DNA damage response. Nature 2000, 404:20I-204

3. Bell DW, Varley JM, Szydlo TE, Kang DH, Wahrer DC and Shannon KE Heterozygous germ line hCHK2 mutations in Li-Fraumeni syndrome. Science 1999, 286:2528-2523

4. Vahteristo P, Bartkova J, Eerola H, Syrjakoski K, Ojala S and Kilpivaara O CHEK2 Genetic Variant Contributing to a Substantial Fraction of Familial Breast Cancer. Am J Hum Genet 2002, 7 I:432-438

5. The CHEK2 Breast Cancer Consortium Low-penetrance susceptibility to breast cancer due to CHEK2*I I00deIC in noncarriers of BRCAI or BRCA2 mutations. Nature Genet 2002, 3 I:55-59

6. Kauff N, Perez-Segura P, Robson M, Scheuer L, Siegel B and Schluger $A$ Incidence of non-founder $B R C A I$ and $B R C A 2$ mutations in high-risk Ashkenazi breast and ovarian cancer families. J Medical Genet 2002, 39:6 I I-6I4

7. Allinen M, Huusko P, Mantyniemi S, Launonen $V$ and Winqvist R Mutation analysis of the CHK2 gene in families with hereditary breast cancer. Br J Cancer 200I, 85:209-2I 2 
8. Begg $C B$ and Berwick $M A$ note on the estimation of relative risks of rare genetic susceptibility markers. Cancer Epidemiol Biomarkers Prev 1997, 6:99-103

\section{Pre-publication history}

The pre-publication history for this paper can be accessed here:

http://www.biomedcentral.com/1471-2350/4/1/prepub

Publish with Bio Med Central and every scientist can read your work free of charge

"BioMed Central will be the most significant development for disseminating the results of biomedical research in our lifetime. " Sir Paul Nurse, Cancer Research UK

Your research papers will be:

- available free of charge to the entire biomedical community

- peer reviewed and published immediately upon acceptance

- cited in PubMed and archived on PubMed Central

- yours - you keep the copyright 